Síntese - Rev. de Filosofia

v. 40 N. 126 (2013): 109-124

\title{
ENTRE A SUTILEZA E A GEOMETRIA: WILLIAM DESMOND E A POROSIDADE DO SER RELIGIOSO
}

(Between Fineness and Geometry: William Desmond and the Porosity of Religious Being)

José Carlos Aguiar de Sousa*

Resumo: $\mathrm{O}$ ethos da modernidade não mais oferece a matriz que nutre a reverência religiosa. $O$ projeto de objetivação e quantificação das coisas implementou um modo de racionalidade ligada ao espírito geométrico que taxa como meramente subjetivas todas as perplexidades últimas da existência humana. Entretanto, estas perplexidades demandam um espírito de sutileza para além do pensamento que medeia apenas consigo. A metaxologia, ou espaço intermediário do ser de William Desmond é um esforço original de repensar as questões ligadas ao ser religioso permanecendo fiel à porosidade que existe entre a religião e a filosofia. $O$ ser religioso demanda aquilo que é mais íntimo em nós e, ao mesmo tempo, o que é mais universal. Este universal íntimo revela a porosidade do ser para além do subjetivismo arbitrário e do objetivismo reducionista. Ele se situa no espaço intermediário que a metaxologia desmondiana busca tematizar. Ao refletir metaxologicamente sobre o ser religioso Desmond não apenas busca resgatar a antiga intimidade entre a filosofia e a reli-

* Doutor em Filosofia, professor do Programa de Pós-graduação em Ciências da Religião da Pontifício Universidade Católica de Minas Gerais, Belo Horizonte, Brasil, e do Instituto Santo Tomás de Aquino (ISTA). Artigo submetido a avaliação no dia 12/12/2011 e aprovado para publicação no dia 19/04/2012. 
gião, mas abre o pensamento para as experiências e acontecimentos elementares que se revelam porosidades para o enigma do ser religioso.

Palavras-chave: Filosofia, religião, subjetivismo, objetivismo, perspectiva metaxológica.

Abstracts: This paper aims to explore the space between religion and philosophy making an effort to rethink the question of being religious in a constructive spirit beyond the modern eros of rational determination. This means to remain true to the porosity that exists between religion and philosophy. By reflecting upon the primordial perplexity of Being, William Desmond tries to find the metaxological or middle space of thought beyond the determination of a thought thinking only itself. Being religious has to do with the intimate universal, in other words, with what is most intimate in us, and yet most universal. This intimate universal reveals a porosity beyond arbitrary subjectivism and reductionist objectivism. It dwells in the between.

Keywords: Philosophy, religion, subjectivism, objectivism, metaxological wiew.

\section{Introdução}

$\mathrm{N}$ ão é uma tarefa fácil encontrar o balanço necessário para se refletir filosoficamente sobre temas que envolvem a realidade última e a religião. O pensamento ocidental desde Platão tem buscado a determinação cada vez mais precisa do ser: ser é ser determinado! A matemática foi privilegiada como o modo mais preciso de determinação do real, por se tratar de uma linguagem neutra e objetiva. Com guinada moderna do pensamento, o ethos da modernidade privilegiou o espírito geométrico que se revelou um terreno árido para a reflexão das perplexidades últimas do ser religioso. Encontrar um espaço intermediário no qual o espírito de sutileza e o espírito geométrico (PASCAL, 1962, p. 244) possam encontrar um balanço representa um grande desafio. A separação entre qualidades primárias e qualidades secundárias taxou de meramente subjetivas todas as perplexidades outras que o caráter determinativo da razão.

A reflexão filosófica sobre a religião nos pede outro modo de atenção-plena que leve o pensamento mais sistemático da tradição filosófica do ocidente para além da mediação da razão autônoma consigo mesma. Isso significa abrir a reflexão filosófica para a porosidade existente no ser, a partir de outro modo do pensar no espaço intermediário entre a filosofia e a religião. A filosofia tem por obrigação pensar os seus outros. Mas existe o enigma do próprio ser que escapa às categorias lógicas do pensamento que se pensa 
a si mesmo. Trata-se aqui da exigência de uma espécie de pobreza da filosofia. Tal pobreza não constitui nenhum demérito para a razão, mais do que situar o pensamento na sua condição intermediária: o espaço metaxológico do pensar. O objetivo deste artigo é refletir sobre as perplexidades envolvidas na relação da filosofia com a porosidade do ser religioso através do pensamento de William Desmond.

\section{O Ser-Entre}

William Desmond é um filósofo irlandês radicado na Universidade de Leuven (Bélgica) e tem sido considerado um dos pensadores mais brilhantes e originais da nova constelação que nutre o debate filosófico atual. Ele recusa o desconstrucionismo afirmando que a retórica da morte do sujeito e do fim da filosofia nos impõe uma dieta anoréxica do pensar. Desmond propõe uma releitura dos clássicos da nossa tradição de pensamento para encontrarmos aberturas sempre novas que iluminem os desafios contemporâneos da filosofia.

Para Desmond, cada ato genuíno do pensamento é uma aventura e nos desafia a pensar a filosofia a partir de uma pluralidade de vozes (plurivocal philosophy) em que a voz lógica e sistemática do pensamento não termine por sufocar as vozes alternativas ao discurso filosófico, que se colocam como 'outras' em relação às formas mais padronizadas (standard forms) da reflexão filosófica. A filosofia deveria permitir que a sua própria voz fosse reformulada pelo impacto dos que lhe são outros significativos tais como a religião, a arte e a ciência. $\mathrm{O}$ filósofo tem que ter algo do poeta, do sacerdote, do cientista dentro de si. (DESMOND, 2000, p. 39-116) Por isso mesmo a metaxologia desmondiana tematiza o "ser entre" (being between) como a matrix existencial que nutre o seu projeto filosófico. (DESMOND, 2000, p. 117-118)

Desmond tenta encontrar um caminho entre os dois extremos presentes no cenário da filosofia contemporânea que ele identifica como sendo as opções hegeliana e wittgensteiniana. Esta última enfatiza que o sentido humano é marcado pela fragmentação ou pluralidade de diferentes formas que não podem ser reduzidas a uma essência unificada. A opção hegeliana tenta um balanço dialético entre a unidade e a pluralidade; todavia, existe a propensão para subordinar a diferença à identidade, muito embora esta não seja uma mera identidade, mas uma univocidade dialética. A opção hegeliana vê a pluralidade das configurações de sentido interligadas pela necessidade dialética, que tem seu culminar na filosofia. A filosofia é, para Hegel, a expressão máxima do espírito absoluto; a arte e a religião também pertencem ao espírito absoluto, mas, embora apresentem um conteúdo absoluto, elas carecem da forma absoluta. Em suma, a opção dialética reduz dialeticamente 
a pluralidade à identidade, enquanto que para a opção wittgensteiniana a possibilidade de qualquer unidade se torna problemática.

O termo metaxológico é derivado do grego "metaxu", que significa meio, intermediário, entre; e "logos", que significa discurso, palavra, fala articulada racionalmente. O sentido metaxológico do ser diz respeito ao logos do metaxu, ou seja, um discurso do "entre" (between), do "meio" (middle). Desmond desenvolve o sentido metaxológico em relação aos sentidos unívoco, equívoco, e dialético. Os quatro sentidos do ser se revelam extremamente complexos. O sentido unívoco se encontra associado à ciência moderna e sua pretensão de determinação total do ser através da matematização e quantificação das coisas. (DESMOND, 1995a, p. 67). O sentido lógico da univocidade perpassa todos os herdeiros de Aristóteles com a afirmação de que ser inteligível é ser determinado tode ti. A consciência unívoca possui uma abordagem englobante em que apenas a identidade é percebida. $\mathrm{O}$ sentido equívoco está mais identificado com Wittgenstein e os jogos de linguagem. (DESMOND, 1995a, p. 80) A oposição dualista do sentido equívoco do ser é vista como justificativa para uma compreensão atomista do ser. A consciência equívoca aponta para zonas de tensão e ambiguidade no ser e no pensar que não permitem uma simples redução à unidade unívoca. Entretanto, se permanecermos nesta equivocidade, o suposto pluralismo que venhamos a defender não constituirá, de fato, uma comunidade, mas algo fragmentado.

O sentido dialético tem como principal interlocutor Hegel. O problema maior do processo dialético é, segundo Desmond, que a alteridade recalcitrante que ele tenta interpretar a partir da noção metaxológica do ser, possa ser reduzida à identidade. Em contraposição a Hegel, um sistema para Desmond deve estar sempre aberto a reconhecer os modos do ser e do pensar que resistem a uma completa conceitualização ou univocidade dialética do ser. Todavia, Desmond quer se distanciar de uma mera caricatura de Hegel e, apesar de criticá-lo, pretende evitar o que ele chama de clichês, derivados de Marx, Heidegger ou Derrida, explorando a possibilidade de uma interação dialética aberta entre a arte, a religião e a filosofia. Desmond se coloca contra algumas atitudes presentes no pensamento pós-hegeliano sobre a tradição metafísica sem necessariamente aceitar a visão Hegel sobre a filosofia especulativa. Desmond se define como estando situado, de modo geral, entre Hegel e os seus críticos. Para ele a filosofia não chega ao seu termo com Hegel e, as velhas questões metafísicas, se apresentam como perplexidades sempre novas para o pensar do presente.

Diferentemente de Hegel para quem o ser puro, sem qualquer determinação, é de fato, o mesmo que o nada, Desmond afirma que existe uma perplexidade primeira, fundante, que inicia o próprio pensar filosófico. Para Desmond, a consciência filosófica não se inicia e muito menos termina com/ou em um argumento. O ser é perplexidade, admiração e sem esta perplexidade ori- 
ginária não haveria a própria consciência (mindfulness) filosófica. Nós experimentamos a maravilha de todas as maravilhas: o ser é!

Neste sentido podemos afirmar que a questão do ser é inevitável. Somos levados a ponderar sobre o que significa existir. A nossa existência está dominada pela tensão entre a identidade (eu) e a alteridade (que é outro ao $\mathrm{eu}$ ). Conforme nos desenvolvemos somos levados a perceber que a identidade-do-eu é, na verdade, muito limitada. A nossa experiência substancia a percepção de uma alteridade que excede todas as determinações e incorporação dentro da própria identidade limitada do eu. A sensação de oposição entre o eu e o outro nos faz sentir certo temor de que o eu possa se perder em face de tal alteridade pervasiva. Desse modo, o eu busca uma mediação, uma união com a alteridade que lhe assegure a sua própria existência, atribuindo à alteridade um papel complementar ao da identidade. Este papel complementar, entretanto, reduz a dinâmica recalcitrante da alteridade a uma homogeneidade da identidade.

A alteridade, por sua vez, força o eu a reconhecer, que muito embora a identidade e a alteridade estejam continuamente em uma proximidade imediata uma da outra, nenhuma delas pode se reduzir à outra. Cresce, então, a consciência da comunidade-do-ser e a questão do ser pede que cheguemos a um ponto comum sobre o que significa participar de tal comunidade.

O problema maior da dialética hegeliana é, segundo Desmond, que a alteridade recalcitrante que ele tenta interpretar a partir da noção metaxológica do ser, tende a ser interpretada por Hegel em termos de um modo de mediação-de-si em última instância fechada. O perigo está em que a alteridade possa ser reduzida à identidade. É preciso estar atento para reconhecer, todavia, que esta forma de identidade é uma identidade sintética que traz em si a diferença, isto é, a alteridade. Ela é uma síntese negativa, uma espécie de identidade absoluta. Esta identidade sintética é denominada por Desmond de univocidade dialética, não consegue, de fato, ultrapassar os limites do eu.

O sentido dialético do ser reconhece o dinamismo transcendente do pensamento e a sua incansável superação de limites, sejam estes tanto as fixações do ser pelo pensamento unívoco quanto as diferenças não-mediadas, diluídas, do pensamento equívoco. O sentido dialético está consciente da impossibilidade de se evitar as questões últimas se quisermos permanecer fieis ao dinamismo inerente ao próprio pensamento. Esta foi umas das intuições mais geniais de Hegel.

Todavia, a mediação da diferença se torna predominantemente mediaçãode-si. Se a atenção-plena metafísica permanecer no sentido dialético do ser, o eu arrisca a se fechar em si mesmo e o processo dialético se torna uma forma fechada de automediação. Tal fechamento resulta, eventualmente, em 
uma univocidade dialética e a atenção-plena metafísica tem que se aventurar mais uma vez e repensar a questão do ser. Isto nos leva a uma postura de intermediação, que Desmond denomina de o "sentido metaxológico do ser". Este novo modo de mediação é, de fato, uma intermediação plural que não pode ser esgotada nem pela mediação do eu nem pela mediação do outro. Em outras palavras, o sentido metaxológico é uma intermediação que envolve a mediação entre a pluralidade de totalidades mediadas por si mesmas (self-mediated wholes). A multiplicidade de instâncias de identidade é colocada lado a lado de tal maneira que a identidade reconhece não apenas a alteridade daqueles que lhe são outros, como também reconhece a si mesma em sua própria exemplificação de alteridade.

Sem dúvida, Hegel é um dos filósofos mais importantes da tradição ocidental. Grande parte do debate filosófico contemporâneo tem em Hegel um dos seus interlocutores privilegiados. Entretanto a ousadia do pensamento hegeliano encontrou muita resistência despertando debates acirrados na metafísica, ética, política e na filosofia da religião. Para Desmond, o retorno dialético do pensamento hegeliano é um retorno à univocidade. Em outras palavras, o absoluto hegeliano é uma totalidade que não consegue de fato se abrir para a diferença recalcitrante das coisas que recusam ser absorvidas na univocidade dialética do pensamento sobre si mesmo.

Para Desmond, o Ser é admiração e esta afirmação não pode ser entendida como um argumento a mais. Somos, por assim dizer, jogados nesta admiração. A nossa existência está dominada pela tensão entre a identidade (eu) e a alteridade (que é outro ao eu). O ser possui um excesso que resiste a qualquer tentativa de conceitualização completa e determinada da metafísica ocidental cujo vôo mais ambicioso é encontrado no espírito absoluto de Hegel.

Aristóteles exprimiu de modo lapidar o excesso do ser ao afirmar: to on legetai pollachos (Aristóteles, Metafísica, 1003b5). Muito embora o ser seja dito de muitos modos, isso não significa que o esforço de se pensar o ser de modo mais determinado seja um exercício que possa ser negligenciado. $\mathrm{O}$ "excesso" do ser se apresenta em uma pluralidade de modos e somente discernindo essas diversas facetas é que poderemos conseguir uma maior clareza do pensar no que se refere à questão do ser. Tal clareza é denominada por Desmond de "atenção-plena-metafísica" (metaphysical mindfulness). (DESMOND, 2000, p. 43-44)

O sentido metaxológico é uma intermediação que envolve a mediação entre a pluralidade de totalidades mediadas por si mesmas (self-mediated wholes). A multiplicidade de instâncias de identidade é colocada lado a lado de tal maneira que a identidade reconhece não apenas a alteridade daqueles que lhe são outros, como também reconhece a si mesma em sua própria exemplificação de alteridade. É exatamente esta interação dinâmica que leva a consciência metafísica para além da mediação-de-si para uma intermediação 
na qual a atenção-plena metafísica é uma participante dentre uma pluralidade de participantes, na comunidade do ser.

\section{O ser religioso $e$ o ethos da modernidade}

Com o advento da modernidade e o seu projeto de objetivação crescente do ser, o mundo foi perdendo paulatinamente os signos do sagrado e a ambigüidade da sua comunicação. Quanto mais o ser do mundo e das coisas se torna objetivado menos ele nos oferece a matriz capaz de nutrir a reverência religiosa. $\mathrm{O}$ ethos científico moderno concebe o mundo em sua pobreza qualitativa como uma mera res extensa. O ethos criado a partir do cogito autônomo tem como consequência a dificuldade profunda da razão moderna de se abrir para algo transcendente ou heteronômico. A guinada para o self é a implementação do projeto da razão que se entende como maître et possesseur de la nature. $\mathrm{O}$ cogito cartesiano cria a sua realidade no próprio ato do pensar; de si e para si o cogito assegura os fundamentos da nova ciência: cogito ergo sum. O caráter autônomo da razão faz com que a racionalidade moderna seja autolegitimadora, não necessitando de um principio externo divino que garanta a verdade de suas próprias operações como fundamento último de certeza.

Distintamente das outras épocas, a modernidade corta o aspecto heteronômico libertando, por assim dizer a curiosidade humana de qualquer elo teológico restringente. O cogito cartesiano é expressão da autonomia do sujeito pensante que não mais necessita de uma referência fora da sua própria estrutura autônoma. O cogito encontra no seu movimento reflexivo o paradigma da verdade. E isso se expressa de forma inequívoca na dedução transcendental kantiana; o "eu penso", julgando por si mesmo, justifica para si a verdade operacional de seus elementos. O sujeito transcendental estabelece as condições a partir de si mesmo para garantir a verdade de seu objeto e do próprio mundo. A primeira certeza do cogito cartesiano é encontrada no próprio ato de reflexão. A pressuposição subjacente a tal certeza é que a consciência não pode ser deduzida de nada além de si mesma. No processo de reflexão a consciência se torna consciente de si e se afirma como autoconsciência. O cogito cartesiano não é um objeto a mais no mundo e por isso mesmo ele pode se colocar como a condição mesma da própria duvida e se apresentar como o principio de certeza fundante de todo o conhecimento. Tudo o mais pode e deve ser exposto a duvida. ${ }^{1}$ Através da própria atividade de reflexão, a autoconsciência cria a sua própria natureza, que é

\footnotetext{
1 Ver o brilhante trabalho de A. B. Gibson, The Philosophy of Descartes, New York: Russell \& Russel, 1967, onde ele discute de forma magistral a nova racionalidade que se impõe a partir do cogito cartesiano.
} 
estar consciente. Em outras palavras, o cogito é tomado como o princípio determinativo de toda racionalidade. Este momento originador de autorreflexibilidade é o que distingue a idade moderna de todas as outras épocas anteriores.

Deus possui apenas a função de assegurar a objetividade da realidade, mas o critério da verdade é dado pelo método: clareza e distinção. A própria ideia de Deus pode ser considerada uma ideia verdadeira por ter sido submetida às novas exigências da razão. Após haver sido assegurada a realidade objetiva do mundo, a ideia Deus não cumpre nenhuma outra função no sistema cartesiano. Tudo o que Descartes deseja de Deus era conseguir estabelecer um lugar para a realidade do mundo dentro do seu sistema, e então ele não necessitava mais dele.

A racionalidade autoafirmativa se torna na modernidade um projeto existencial. No princípio normativo do cogito é que encontramos a estrutura de toda a racionalidade subsequente. A estrutura da racionalidade moderna pode ser delineada a partir da unificação dos dois polos constituintes do princípio da autonomia moderna: autopreservação e auto-afirmação-dosujeito. A racionalidade moderna é estruturalmente constituída em termos de uma trindade de componentes, que se delineiam em três momentos paradigmáticos: identidade, atividade autopreservadora e contradição.

O primeiro momento estrutural, identidade, nos faz confrontar-nos com um novo sujeito cuja consciência autoafirmativa se coloca como o principio subjacente de toda a racionalidade. A consciência se torna causa sui. (SOUZA, 2005, p. 119.) O segundo momento estrutural de atividade autopreservadora, nos faz confrontar com uma atividade que não está direcionada a nenhuma teleologia ou fim pré-estabelecido, já que a sua moção visa apenas a preservação-de-si-mesma. Este princípio de autopreservação foi o responsável pela destruição do princípio de teleologia que norteou toda a tradição do pensar até a idade moderna. E por isso mesmo, ele é a inversão de toda e qualquer teleologia. (SOUZA, 2005, 119) Nós encontramos o terceiro momento estrutural, contradição, de forma bem clara e evidente na concepção newtoniana do espaço e do tempo. De fato, a Lei da Inércia de Newton é o ponto central do princípio de autopreservação. A concepção newtoniana de espaço superou a concepção de que o telos do movimento é o repouso. Para Newton a mudança do curso de um objeto se dá devido a fatores externos ao objeto. Estes fatores externos contradizem o curso normal de um dado movimento. (SOUZA, 2005, p. 120)

A razão advoga uma universalidade neutra, liberta de todas as particularidades trazidas pela religião. $\mathrm{O}$ ethos moderno é geométrico e não mais contemplativo. Não existe nada mais a ser contemplado a não ser a universalidade neutra da razão geométrica. E o sucesso metodológico da ciência no projeto de dominar a natureza fez do conhecimento cientifico o paradigma de todo o conhecimento. (WHITEHEAD, 1985, p. 70). Assim sendo, todos os 
outros possíveis modos de se descrever a realidade não possuem o suposto grau determinativo da razão científica. A matemática passou a ter importância impar na formação de ideias. E a matemática é completamente neutra a todas as questões que envolvem valor. (WHITEHEAD, 1985, p. 38) A noção de explicação mecânica para todos os processos da natureza finalmente adquiriu na modernidade o status de dogma da ciência por assim dizer. (WHITEHEAD, 1985, p. 75) O mundo nada mais é do que uma sucessão de configurações instantâneas de matéria: res extensa.

\section{O ser religioso e a dupla exigência do pensamento}

O mundo objetivado da ciência não é mais uma matriz capaz de nutrir a reverência religiosa como no passado. Não existe mais lugar para a comunicação ambígua dos sinais sagrados. A modernidade ocidental testemunhou a atenuação do espírito de sutileza, permitindo no máximo a moralização da religião: o deísmo moral kantiano. (DESMOND, 2005, p. 7) A questão de Deus não é uma questão do entendimento ou razão determinativa, mas um problema da razão prática. Para Kant, Deus é impossível de ser conhecido, mas ele é necessário do ponto de vista da moralidade.

O ideal científico operado pela ciência moderna com a sua pretensão de dar uma resposta unívoca ao ser das coisas se torna reticente em relação à matriz ambígua do ser religioso, que nutriu a racionalidade do passado. A metaxologia desmondiana busca refletir sobre o espaço intermediário entre a religião e a filosofia. Isso exige explorar de modo sistemático os temas presentes na filosofia da religião. Entretanto, o pensamento metaxológico explora temas que se encontram no limite da compreensão mais sistemática do pensar forçando a filosofia a se abrir para perplexidades outras que não a determinação do pensamento autônomo moderno.

O ser religioso demanda uma dupla exigência: intimidade e universalidade. De fato, as questões últimas tocam o que existe de mais intimo em cada um de nós: o coração. Ao mesmo tempo o seu apelo possui um caráter de universalidade na medida em que se destina para todos. Em outras palavras, o ser religioso demanda que permaneçamos no espaço entre o que é mais intimo em nós e o que é, ao mesmo tempo, mais universal. (DESMOND, 2005, p. 5.) Tratase de um universal íntimo na medida em que ele tem que tocar o que é mais profundo em nós ao mesmo tempo que essa relação de intimidade é oferecida a todos os seres humanos. Trata-se de uma exigência de intimidade e de universalidade que desafiam o pensamento filosófico. Não se trata de uma intimidade meramente subjetiva; ao mesmo tempo não se trata de uma universalidade neutra, impessoal e homogênea. $O$ desafio é buscar um balanço que nos permita refletir filosoficamente sem trair o aspecto íntimo do ser religioso nem abandonar o caráter universal que ele apresenta. 
A filosofia neste espaço intermediário tem que estar plenamente atenta à frágil ambiguidade do ser religioso ao mesmo tempo que é levada para os limites do pensamento mais sistemático ao tratar de temas que exigem mais do que o espírito geométrico pode alcançar. O ser religioso demanda um espírito de sutileza que vá alem do sentido moderno de teoria, que parte da hipótese instrumental que nos oferece entendimento e domínio da realidade.

O ser-religioso tem que ser abordado por um espírito do sutileza capaz de se abrir para a porosidade do mistério elusivo das coisas, especialmente, para o mistério de Deus. O ser-religioso nos mostra algo último, mais próximo do amor do que de uma teoria analítica ou da clareza geométrica da ciência. A univocidade da teoria cientifica não é capaz de penetrar a matriz ambígua do ser. A religião nos coloca frente a algo que excede o caráter meramente autodeterminativo do pensamento geométrico. A filosofia, segundo Desmond, tomada como mera tecnicalidade puramente argumentativa não consegue abarcar o caráter excessivo do ser religioso.

Desmond demonstra, tomando Sócrates como exemplo, a origem religiosa da filosofia, que precipitou a própria perplexidade filosófica. Apesar das diferenças entre as duas existe uma intimidade profunda entre a religião e a filosofia. A religião não é algo apenas existencial e subjetivo na medida em que leva em consideração um senso de comunidade, de uma experiência histórica, possuindo assim um caráter temporal. Ela é participação no íntimo universal que revela o nosso ser em relação à realidade última. Tratase de uma universalidade não objetivável e de uma intimidade não subjetivável. (DESMOND, 1995a, p.31) Ela aponta, segundo Desmond, para as "hipérboles do ser". (DESMOND, 2005, p. 13) Ou seja, a religião aponta para acontecimentos que se colocam em excesso em relação à completa determinação finita do pensamento, para além da objetivação e da subjetivação. Eles devem ser pensados tanto como algo íntimo que ao mesmo insinua algo universal. (DESMOND, 2005, p. 13)

A filosofia tem que se mover para além do "postulado finitista" e seu enunciado básico de que ao pensar o ser como finito e nada mais do que finito, então, não é possível pensar nada além. (DESMOND, 2005, p. 25.) A questão do ser religioso não emerge dentro do ethos do pensar que não considera nada além do que o postulado finitista permite. O questionamento desmondiano é direcionado às filosofias da imanência radical que fecham o pensamento a tudo o que é alternativa a ele. Ao advogar a pobreza da filosofia a metaxologia força os filósofos a se abrirem para além das autossatisfações do conhecimento mais sistemático da filosofia tradicional. Assim, novas porosidades do pensar podem aflorar de modo mais rico e promissor do que o exercício da filosofia enquanto pensamento que se pensa apenas a si mesmo.

Trata-se de outro modo de comunicação entre a filosofia e a religião. Neste sentido o pensamento desmondiano se coloca em oposição ao saber absoluto de Hegel. Para Desmond, o ser religioso requer que a filosofia pense nos 
limites do próprio um espaço "entre" que não pode ser expresso ou traduzido em termos da automediação da totalidade imanente nos moldes do absoluto hegeliano, para alem do qual não existe nada. A busca do conhecimento é mais do que a cognição determinada, é mais do que o autoconhecimento do pensamento que medeia consigo mesmo.

Em suma, o pensamento se esvazia por assim dizer de sua pretensão à completa determinação do ser e se coloca na dimensão do hiperbólico (DESMOND, 2005, p. 20) que vai alem da cognição determinada das ciências. Trata-se de uma espécie de retorno ao zero: uma profunda abertura ao enigma ontológico do ser. (DESMOND, 2005, p. 13) Existem espaços que são "entres" e estes se constituem como poros de comunicação entre o pensamento e o que é outro em relação ao pensamento. Esta porosidade encontrase aberta à realidade última sendo requerida uma sutileza do pensar para adentrarmos o universal íntimo. Para Desmond, quando nos referimos à realidade última temos que entrar num processo de transformação da nossa atenção-plena para entender a alteridade daquilo que é último. Caso contrário, iremos apenas refletir nossa própria imagem ou o nosso próprio meio autônomo de determinação ao tentamos determinar a realidade última reduzindo-a equivocamente a essa ou àquela coisa.

\section{A porosidade do ser religioso e a pobreza da filosofia}

É necessário que a filosofia se esvazie de seu eros de total conceituação determinada do ser para ir ao encontro dos grandes poetas e figuras religiosas. Assim, a plena-atenção metafísica é capaz de se colocar numa dimensão hiperbólica superando os limites do pensamento que medeia consigo mesmo (DESMOND, 2005, p. 20). Este esvaziamento revela o que Desmond denomina de "pobreza da filosofia" e faz despertar algo relativo à urgência das questões últimas. Anterior ao conatus essendi nós encontramos o passio essendi. (DESMOND, 2005, p. 23) Ou seja, trata-se do reconhecimento de que todos os esforços ou empreendimentos do pensar pressupõem algo mais primordial.

Em outras palavras, existe uma dupla exigência de que nos relacionemos com o outro enquanto outro ao mesmo tempo em que buscamos autodeterminação e totalidade. Esta tensão que nos leva a reconhecer o caráter irredutível da alteridade dos outros que nos transcendem e a totalidade, (DESMOND, 1995a, p. 165.) se encontra refletida na tensão existente entre passio essendi e conatus essendi. Este último pode ser visto de tal modo que nega a dependência do outro, implícita na passio essendi. O resultado é um tipo de autodeterminação e vontade de potência incapaz de reconhecer que é o dom do ser percebido na passio que torna possível o conatus. 
Existe um tipo de perplexidade que Desmond identifica como sendo "erótica" e que se liga ao desejo de superar a indeterminação do início, até se tornar completamente determinada pelo pensamento que se pensa a si mesmo. A razão autônoma tenta um controle do objeto reduzindo as equivocidades desconcertantes em nome de univocidades que não conseguem abarcar as ambiguidades do ser.

Todavia, podemos pensar outros modos de perplexidade e de transcendência que não se ligam ao ato de autotranscendência. A perplexidade pode ser agápica. A porosidade do ser revela algo supradeterminado, hiperbólico e que, por isso mesmo, não pode ser circunscrito pelo movimento do pensamento que medeia consigo mesmo. Isto não significa abrir mão do pensamento filosófico, mas ir além do sucesso da mera teoria para um novo tipo de pensar no espaço "entre" a filosofia e os seus outros. (DESMOND, 2005, p. 25)

Desmond advoga um tipo de perplexidade, por ele denominada de perplexidade agápica que demonstra uma generosidade frente à alteridade das coisas; ele utiliza a metáfora da "mente agápica," enquanto um modo de plena-atenção metafísica, no qual o pensamento busca, de fato, aquilo que é outro, em sua alteridade peculiar, ao próprio pensamento. Este se distingue da mente erótica associada com a metafísica desde Platão e que a partir do século XVII passa a exercer um tipo de soberania que visa o controle das coisas através do projeto de maestria e senhorio da natureza: a soberania erótica. Através da determinação limitada da identidade originada pelo eros, torna-se problemático reconhecer a caráter ambíguo do ser em sua alteridade mais genuína.

O caráter agápico do pensamento da identidade e da alteridade, proposto por Desmond deve ser visto como absolutamente básico ou fundamental. $\mathrm{O}$ dinamismo da alteridade agápica é o que mais acuradamente reflete a riqueza e a completude do ser. (DESMOND, 1992, p. 78-80) Faz-se necessário transcender o sujeito, indo além da imediação, passando pela automediação, para um nível de intermediação que se dá no sentido metaxológico do ser. A perplexidade agápica é impulsionada pela plenitude anterior da transcendência para uma relação genuína com o outro enquanto outro. (DESMOND, 1995a, p, 326.)

A intermediação metaxológica, de acordo com Desmond, nos leva a uma identidade mais completa do sujeito ao reconciliar a identidade e a alteridade. Assim sendo, através da percepção da intermediação entre a identidade e a alteridade, o sentido metaxológico do ser pode nos transportar de um momento erótico para um momento agápico, que é o resultado de uma plena-atenção de intermediação aberta. A concepção metaxológica se inicia com a afirmação do ser como um excesso positivo. Nenhum método reflexivo será capaz de sobrepujar ou mesmo capturar a energia criativa, que faz com que o devir desabroche no ser. A filosofia é uma atividade do meio e 
nesta intermediação metaxológica com as vozes dos que lhe são outros, a própria voz filosófica pode ser modificada. Este é um risco saudável que a filosofia não deve ter medo de correr.

A porosidade primordial do ser se encontra expressa de modo mais íntimo no ser religioso. Na medida em que o próprio pensamento se encontra enraizado nessa porosidade primeira, a própria filosofia é derivativa dessa porosidade primordial e por isso mesmo ela é digna juntamente com a religião e a ciência de uma mesma reverência. Todavia, o ser religioso se encontra mais próximo das raízes dessa reverência. Isso significa que o próprio pensamento ou perplexidade erótica participa dessa mesma porosidade. Em seu delineamento histórico o pensamento ocidental se afastou da reverência primeira do ser.

A perplexidade erótica possui, contudo, uma ambiguidade: na medida em que traz consigo a exigência dupla de autocompletude e totalidade, ela não pode deixar de algum modo de se abrir para a alteridade ou transcendência do outro. Desmond vê essa ambiguidade refletida no mito de Eros narrado por Diodima no Simpósio de Platão. Eros é filho de Penia ou pobreza e de Poros ou plenitude. (DESMOND, 2005, p. 23.) Assim sendo, existe uma ambiguidade inerente à perplexidade erótica entre a completude e a carência, entre eros e ágape. A perplexidade tende a ser erótica na medida em que vai ao encontro do outro para obter algum modo de completude, totalidade ou segurança para o self. O outro como meio de autocompletude. (DESMOND, 1995b, p. 117.) O que motiva a penia ou carência do eros é o conatus essendi. Todavia, pode haver um retorno para o poros presente no eros, que possibilite à perplexidade erótica encontrar o excesso primeiro (passio) e a completude que ele deseja desde o início.

A perplexidade erótica indeterminada é uma atenção-plena equívoca que busca determinar o ser das coisas sem levar em consideração que a raiz de toda determinação se encontra na alteridade supradeterminada. Para Desmond, poros esta relacionado com porosidade, que se encontra na raiz do ser religioso. Na própria carência encontramos algo relacionado intimamente com porosidade e que não é apenas simples expressão da vontade de potência do pensamento. (DESMOND, 2005, p. 23.)

\section{Considerações Finais}

O ethos da racionalidade instrumental, privilegiado pela guinada da modernidade, implementou um dualismo entre a objetivação do ser das coisas e a subjetivação dos valores. Esse dualismo entre fato e valor tornou problemática a questão do ser religioso e da transcendência outra que não a autotranscendência da própria razão. Para Desmond o que se perde com 
um mundo destituído dos signos do sagrado é a riqueza ambígua do "entre". (DESMOND, 2005, p. 19.) O problema do ser religioso na modernidade pode ser descrito em termos da antinomia da autonomia e da transcendência. A guinada moderna absolutizou a autonomia da razão. O que permaneceu foi uma transcendência relativizada que nada mais é do que a projeção das nossas próprias potências. A razão instrumental implementa um projeto ligado a um modo de soberania que Desmond denomina de soberania erótica. O self exerce uma soberania que busca dominar tanto o outro quanto a si mesmo como totalidade automediadora no círculo fechado sem uma abertura genuína ao outro em sua alteridade. Torna-se extremamente delicado falar do ser religioso no mundo desencantado e automediado da modernidade.

A metaxologia desmondiana é uma visão do ser que implica alteridade genuína, transcendência e diferença: o ser é um excesso supradeterminado constituído por uma genuína diferença. $\mathrm{O}$ ser religioso nos pede reverência e perplexidade frente ao mistério último do ser, que hiperbolicamente se refere à origem agápica, para além da origem erótica associada ao movimento automediador do pensamento. (DESMOND, 1995a, p, 41.) O ser religioso se expressa em termos de gratidão e generosidade, fruto do reconhecimento dos dons da origem agápica. Por isso mesmo o ser religioso é sabático na medida em que reconhece e celebra a bondade de toda a criação.

Existe uma intimidade singular no ser religioso, uma porosidade, que se relaciona com a passio essendi e, que se traduz na paciência ou receptividade do pensamento agápico ante a completude do ser. Essa porosidade é anterior ao conatus essendi. Antes de nos abrirmos ativamente ao outro em busca das determinações do pensar estamos abertos à supradeterminação íntima da transcendência que é outra em relação à nossa própria autotranscendência.

A alteridade excessiva do ser não pode ser plenamente capturada por uma razão meramente instrumental e pela oposição dualista entre a objetivação do ser e a subjetivação dos valores implementada na modernidade. O que se perde com esse dualismo entre fato e valor é a riqueza do espaço metaxológico do ser. O mundo totalmente objetivado é destituído dos sinais e dos traços do sagrado. A modernidade absolutizou a autonomia humana e, por conseguinte, o ethos moderno não consegue reconhecer a alteridade genuína do sagrado. $\mathrm{O}$ que resta é uma transcendência relativizada que sobrevive como mera projeção de nossos próprios poderes. Como resultado, uma indiferença em relação às questões da religião e de Deus na modernidade.

O percurso desse novo ethos de indiferença pode ser traçado do sujeito autônomo que se torna o árbitro epistêmico do mundo (Kant) ao Geist como origem racional do desdobrar-se do mundo (Hegel) e deste até a vontade cega como origem de todas as coisas (Schopenhauer). Para Desmond, a 
religião esta intimamente ligada à raiz ontológica das coisas em sua mais profunda e íntima matriz. Ela revela certa porosidade para além do finitismo moderno. Para ele a religião não é uma dimensão meramente privada ou interior da vida, mas diz respeito ao nosso próprio estar no ser enquanto tal: o nosso ser em relação com a origem supradeterminada do ser. O ser religioso leva o pensamento para além, para um modo de sabedoria idiótica, cuja intimidade é porosidade. O resultado é gratidão e generosidade frente à origem agápica do ser.

Desse modo, Desmond introduz um novo modo de se refletir sobre as perplexidades últimas da existência. Ele concebe o pensamento de modo intermediário numa plurivocidade de vozes. Ao reconhecer genuinamente as vozes dos que lhe são outros, o pensamento é levado a se aventurar até além dos limites do próprio pensar mais sistematizado. A filosofia tem que pensar os seus outros. Mas nos limites do próprio pensamento ela é confrontada com uma porosidade que aponta para além das formas mais sistemáticas do pensar, que aponta, entre a geometria e a sutileza, para o reconhecimento da bondade do ser para além do bem meramente instrumental da razão moderna.

\section{Referências Bibliográficas}

DESMOND, William. Philosophy and Its Others: Ways of Being and Mind. Albany: State University of New York Press, 1990.

DESMOND, William. A Filosofia e os Seus Outros: Modos do Ser e do Pensar. São Paulo: Loyola, 2000.

DESMOND, William. Beyond Hegel and Dialectic: Speculation Cult and Comedy. Albany: State University of New York Press, 1992.

DESMOND, William. Being and Between. Albany: State University of New York Press, 1995a.

DESMOND, William. Perplexity and Ultimacy: Metaphysical Thoughts from the Middle. Albany: State of University of New York Press, 1995b.

DESMOND, William. Is There a Sabbath for Thought? Between Religion and Philosophy. New York: Ford ham University Press, 2005.

DESMOND, William. Hegel's God: A Counterfeit Double? Asdershot: Ashgate, 2003.

DESMOND, William. "Being Between." Clio: A Journal of Literature, History and the Philosophy of History 20.4 (1991): 305-331.

DESMOND, William. "Between Finitude and Infinity: Hegelian Reason and Pascalian Heart." Hegel on Modernity. Ed. A. Collins. Albany: State University of New York Press, 1995c. 
BERNSTEIN, Richard J. The New Constellation: The Ethical-Political Horizons of Modernity/Postmodernity. Cambridge: Polity Press, 1991.

FINKIELKRAUT, Alain. La Défaite de la Pensée. Paris: Gallimard, 1987.

HOY, David Couzens. "A history of consciousness: from Kant and Hegel to Derrida and Foucault", History of the Human Sciences vol. 4 No.2 (1991): 261- 281;

PASCAL, Blaise. Pensées. Texte établi par Louis Lafuma. Paris: Éditions du Seuil, 1962.

SOUZA, José Carlos Aguiar de. O Projeto da Modernidade. Brasília: Libris Livro, 2006.

VAZ, Henrique C.Lima. Escritos de filosofia VII: raízes da modernidade. São Paulo: Loyola, 2002.

WHITEHEAD, A. N. A função da razão. Trad. Fernando Dídimo. Brasília: Editora da UNB, 1985.

Endereço do Autor:

Pontifícia Universidade Católica de Minas Gerais

Programa de Pós-graduação em Ciências da Religião

Av. Dom José Gaspar 500 - Coração Eucarístico

30535-901 Belo Horizonte - MG

jc-aguiar@ig.com.br 